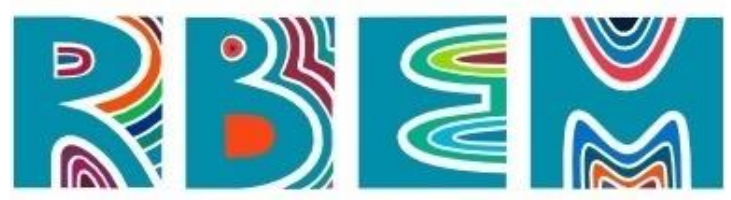

REVISTA BAIANA dE EDUCAÇÃO MATEMÁtICA

\title{
ARTIGO
}

dol https://doi.org/10.47207/rbem.v1i.10303

\section{Construção de Materiais Pedagógicos: contribuições no ensino de matemática para alunos surdos}

\author{
COSTA, Walber Christiano Lima da \\ Profess or da Faculdade de Ciências da Educação (FACED/ICH da UNIFESSPA). Doutor em \\ Educação em Ciências e Matemáticas (PPGECM/IEMCI/UFPA). \\ https://orcid.org/0000-0003-2440-8564. walberchristiano@gmail.com
}

SILVA, Kelvia Nunes da

Discente do Curso de Pedagogia. Bolsista PIBEX (UNIFESSPA). https://orcid.org/0000-0001-7198-5108. kelviasilvan22@gmail.com

Resumo: O presente texto objetiva apresentar os resultados do projeto de iniciação científica, vinculado à Universidade Federal do Sul e Sudeste do Pará - UNIFESSPA, intitulado "Construção de materiais pedagógicos no ensino de matemática para alunos surdos" ". Tal projeto objetivou construir materiais pedagógicos que proporcionem uma aprendizagem mais adequada aos surdos no ensino de Matemática. Nossa abordagem é a qualitativa, pois a partir dos materiais construídos, pudemos verificar as aprendizagens dos alunos em relação à matemática. Constatamos que dentro das experiências vivenciadas, evidencia-se que a construção de materiais pedagógicos e a utilização do mesmo deve sempre partir da necessidade do aluno percebida pelo professor, sendo esse material o mediador por auxiliar a percepção visual do surdo, mas não como o único meio de aprendizagem.

Palavras-chave: Materiais Pedagógicos. Surdos. Libras.

\section{Construction of Pedagogical Materials: contributions to the teaching of mathematics to deaf students}

\begin{abstract}
This text aims to present the results of the scientific initiation project, linked to the Federal University of the South and Southeast of Pará - UNIFESSPA, entitled "Construction of pedagogical materials in the teaching of mathematics for deaf students". This project aimed to build pedagogical materials that it provides a more appropriate learning for the deaf in the teaching of Mathematics. Our approach is qualitative, because from the constructed materials, we were able to verify the students' learning in relation to mathematics. We found that within the lived experiences, it is evident that the construction of pedagogical materials and the use of it must always start from the student's need perceived by the teacher, this material being the mediator for helping the visual perception of the deaf, but not as the only means of learning.
\end{abstract}

Keywords: Pedagogical Materials. Deaf. Libras.

\footnotetext{
1 O projeto foi apresentado na forma de Comunicação durante o I ENEMI - Encontro Nacional de Educação Matemática. Diante do Vínculo do Projeto com a Instituição de Ensino Superior, alguns resultados foram apresentados durante o VI Seminário de Iniciação Científica.
} 


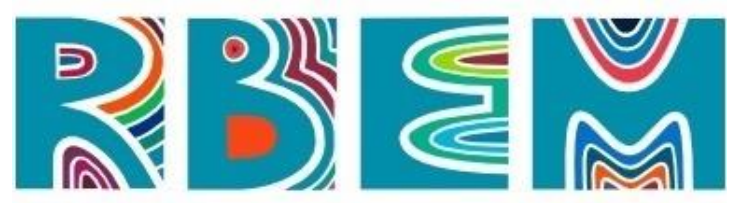

REVISTA BAIANA DE EDUCAÇÃO MATEMÁTICA

\title{
Construcción de Materiales Pedagógicos: aportes a la enseñanza de las matemáticas a estudiantes sordos
}

\begin{abstract}
Resumen: Este texto tiene como objetivo presentar los resultados del proyecto de iniciación científica, vinculado a la Universidad Federal del Sur y Sureste de Pará - UNIFESSPA, titulado "Construcción de materiales pedagógicos en la enseñanza de las matemáticas para estudiantes sordos". Este proyecto tuvo como objetivo construir materiales pedagógicos que proporcionen un aprendizaje más apropiado para los sordos en la enseñanza de las matemáticas. Nuestro enfoque es cualitativo, ya que a partir de los materiales construidos pudimos verificar el aprendizaje de los estudiantes en relación a las matemáticas. Encontramos que dentro de las experiencias vividas, es evidente que la construcción de materiales pedagógicos y el uso de los mismos debe partir siempre de la necesidad del alumno percibida por el docente, siendo este material el mediador para ayudar a la percepción visual de los sordos, pero no como el único medio de aprendizaje.
\end{abstract}

Palavras-Clave: Materiales Pedagógicos. Sordos. Libras.

\section{Introdução}

A educação básica brasileira, desde o advento da Lei de Diretrizes e Bases da Educação Nacional - LDBEN (BRASIL, 1996), tem apresentado algumas transformações. No que diz respeito à educação de pessoas com deficiência, observamos que a partir de 1996 a presença deste público nas salas de aula regulares se tornou mais frequente. Sabemos que desde a Constituição Federal de 1988 (BRASIL, 1988) é garantido o direito do atendimento especializado de preferência na rede regular de ensino, porém a partir da LDBEN a sociedade começou a proporcionar um maior reconhecimento a essa necessidade, trazendo a luz um conceito muito utilizado na contemporaneidade, o de inclusão educacional.

Ressaltamos para que haja um alcance efetivo de uma inclusão, deve haver oportunidades de qualidade a partir das diferenças de cada um. No caso da pessoa surda, alguns aspectos precisam ser analisados. A presença da Língua Brasileira de Sinais (Libras) é um dos itens fundamentais para que possamos ver a inclusão do surdo nas escolas. Aliado a isso, vemos a presença de professores capacitados, de materiais pedagógicos adequados e do profissional Tradutor-Intérprete de Libras. Acerca do tema materiais pedagógicos, compreendemos que muitas vezes a falta de recursos impede a aquisição de materiais sofisticados. Assim, vemos a importância de um trabalho de incentivo à construção de materiais pedagógicos que sejam acessíveis às realidades financeiras de nossas escolas públicas. 


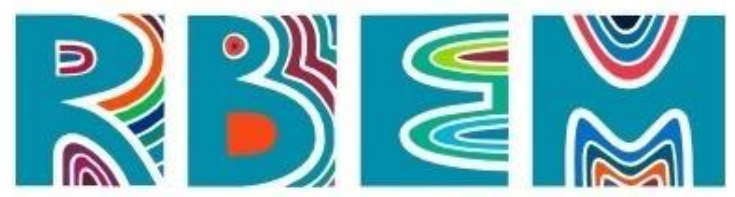

REVISTA BAIANA DE EDUCAÇÃO MATEMÁtICA

A LDBEN (BRASIL, 1996) aponta-nos para a necessidade de uma educação significativa que permita explorar as capacidades dos indivíduos de maneira a respeitar as diversas culturas e aspectos sociais para assim promover o direito a educação de qualidade. Freire (1987) explicita que a educação é um ato político que serve para promover a liberdade e igualdade e que essa ocorre quando a realidade do aluno é o objeto para o ensino e para a aprendizagem de conteúdos didáticos.

Nesse sentido, a educação especial vem se desenvolvendo de modo a atender às necessidades especificas de determinados alunos, intensificando a inserção desses dentro das salas regulares de educação, promovendo a inclusão. Outro avanço para a educação especial vem a ser a Lei Brasileira de Inclusão - LBI de 2015 visto que é uma das leis mais atual sobre essa temática, o que corrobora para que de fato o acesso à escola seja um direito de todos como é afirmado na Constituição Federal de 1988 (BRASIL, 1988).

Dentro da perspectiva dos avanços legislativos e práticos para que se efetive uma educação especial e que seja significativa, encontramos avanços no campo da educação matemática para modificar o seu ensino tradicional, visto que em 2013 a Sociedade Brasileira de Educação Matemática (SBEM) inclui um grupo de trabalho - GT 13 nominado Diferença, Inclusão e Educação Matemática objetivando desenvolver estudos na área. A partir desse grupo, tem-se visto avanços no que se relaciona a temática do ensino da matemática aos alunos surdos, ainda que seja essa uma abordagem recente no meio teórico (COSTA et al, 2018).

Dentro dessa perspectiva de inclusão especificamente de alunos surdos nas aulas de matemática, percebe-se que a preocupação é significar os conteúdos dessa disciplina para esse público. Acerca desse processo é viável que para isso se reconheça a cultura surda destacada por Strobel (2008) por possuir uma Língua de Sinais e a experimentação do mundo por meio da visão. Valorizando a cultura surda, o ensino e a aprendizagem da disciplina é facilitado para os alunos surdos de modo que não ocorre uma subjugação desses indivíduos e nem imposição da cultura ouvinte.

Nesse viés a Libras tem um papel importantíssimo, mas ao que tem se destacado é inserção da pedagogia visual dentro desse campo de modo a que esse seja o melhor meio para se alcançar a '[...] capacidade de captar e compreender o 'saber' e a 'abstração' do pensamento imagético dos surdos" (CAMPELLO, 2007, p. 130). Daí que os recursos didáticos, materiais 


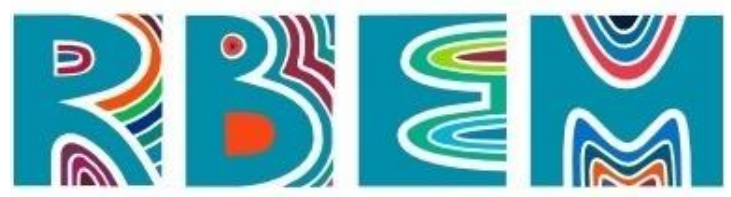

REVISTA BAIANA dE EDUCAÇÃo MATEMÁtICA

pedagógicos ou materiais didáticos como denominado por Lorenzato (2010) facilitam esses processos de aprendizagem do surdo por proporcionar informações a partir do campo visual.

Diante do exposto, destacamos que o presente texto tem como objetivo apresentar os resultados do projeto de iniciação científica, vinculado à Universidade Federal do Sul e Sudeste do Pará - UNIFESSPA, intitulado "Construção de materiais pedagógicos no ensino de matemática para alunos surdos. O projeto foi vinculado ao Edital PIBIC/CNPQ Nº6/20192020, vinculado à Pró-Reitoria de Pós-Graduação, Pesquisa e Inovação Tecnológica (PROPIT) da Unifesspa e teve vigência de 01/08/2019 a 31/07/2020.

\section{Fundamentação Teórica}

A Educação matemática, enquanto campo de pesquisa no Brasil tem avançado consideravelmente nessas primeiras décadas do século XXI. Historicamente não há uma concreta certeza acerca do início de estudos e pesquisas nessa área, porém o boom científico se atribui a dois momentos importantes: o Movimento da Matemática Moderna (ocorrido em meados da década de 1960, que provocou mudanças nas práticas escolares no ensino da disciplina) e a publicação, em 1995, do texto de Dário Fiorentini intitulado "Alguns modos de

\section{D) BEVISTA} MATEMACÁOCA SE ver e conceber o ensino da matemática no Brasil'. Tal texto inaugura de forma direta o uso das tendências em educação matemática e, consequentemente, acabou por influenciar ainda mais pesquisas da educação matemática. A educação brasileira como um todo, desde a promulgação da Constituição de 1988, apresenta imperativos e reflexões visando melhorias nos processos de ensino e de aprendizagem. Em 1996, surge a LDBEN que, além de seguir os pensamentos da Constituição, apresenta ainda algumas informações sobre públicos mesmos favorecidos em relação aos demais membros da sociedade, como as pessoas com deficiência.

Ainda no país destacamos a LBI de 2015, legislação mais atual em prol dos direitos educacionais das pessoas com deficiência. Mantoan (2003, p.16) acerca da inclusão destaca que

$\mathrm{Na}$ perspectiva inclusiva, suprime-se a subdivisão dos sistemas escolares em modalidades de ensino especial e de ensino regular. As escolas atendem às diferenças sem discriminar, sem trabalhar à parte com alguns alunos, sem estabelecer regras específicas para se planejar, para aprender, para avaliar currículos, atividades, avaliação da aprendizagem para alunos com deficiência (MANTOAN, 2003, p. 16). 


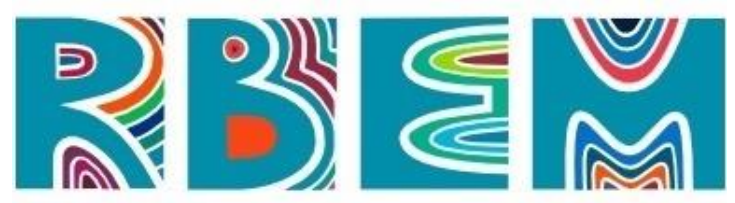

REVISTA BAIANA dE EDUCAÇÃO MATEMÁtICA

A partir desse momento histórico, observamos que as pessoas com deficiência começaram a aparecer mais nos cenários das classes regulares, haja vista que, até antes de 1996, as escolas especiais eram o local principal de estudo dessas pessoas. Surgem aí, nesse processo de inclusão, algumas questões sérias nas escolas, como fortes resistências ao acolhimento da pessoa com deficiência ante a maior parte do público que não manifestava deficiência. Uma barreira que também consideramos séria foram as dificuldades de muitos docentes em conseguir utilizar estratégias metodológicas favoráveis à aprendizagem das pessoas com deficiência. E, dependendo da especificidade, a escolha metodológica tem de ser diferente. Nesse contexto, imaginemos o ensino de disciplinas consideradas por muitos alunos como de difícil compreensão como a Matemática. Neste contexto da educação inclusiva, surgiu o movimento que chamamos de Educação Matemática Inclusiva.

A SBEM, entidade máxima no que diz respeito aos reconhecimentos científicos em relação à área educação matemática - percebeu os grandes avanços e necessidades de a educação matemática inclusiva ter seu espaço cada vez mais consolidado, de modo que, em 2013, oficializou o Grupo de Trabalho 13, o GT13 - Diferença, Inclusão e Educação Matemática. Costa (2017) apresenta que a educação matemática inclusiva é uma área crescente, em que pesquisadores, a cada momento, destacam inquietações contemporâneas, as quais, muitas vezes, surgem a partir das necessidades presentes no cenário escolar.

De fato, sabemos que após a promulgação da LDBEN de 1996, as pessoas com deficiência começaram a ganhar destaque nas classes regulares e com isso foram necessárias reflexões sobre como a atuação escolar pode favorecer as aprendizagens desse público. Costa (2017) ainda esclarece que, no ensino de matemática, muitos fatores precisam ser analisados e que a educação matemática inclusiva ajuda a partir das pesquisas científicas.

Mantoan (2003) argumenta que a inclusão não sinaliza por privilégios as pessoas com deficiência, mas sim a oportunidade de acessibilidade para um cenário de igualdade de condições a todos, independente da especificidade da pessoa. Com isso, inferimos que na educação matemática inclusiva oportuniza, às pessoas no cenário escolar, o entendimento de que adaptações sejam necessárias para que possa haver aprendizagem em relação aos conteúdos da disciplina.

Borges e Nogueira (2013) afirmam que no caso dos alunos surdos, há um fator importante a ser pesquisado: a Libras. Como esta é uma língua viva e o Brasil é um país de 


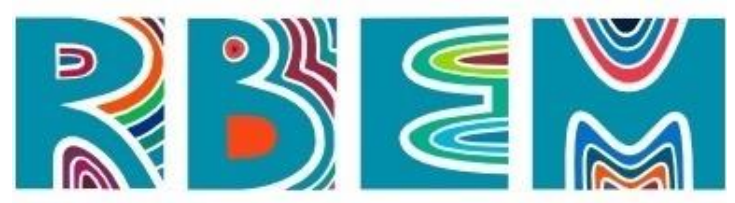

REVISTA BAIANA DE EDUCAÇÃO MATEMÁtICA

dimensões continentais, diversas questões ainda devem ser explicitadas, como por exemplo, em que no ensino de matemática ainda não há sinais padronizados e específicos para palavras como, por exemplo, logaritmos. Vemos com isso que a educação matemática inclusiva, enquanto campo científico pode colaborar com problematizações como essa que ocorre no ensino da disciplina com surdos.

Gesser (2009) apresenta que a Libras é uma língua completa e que podemos expressar qualquer ideia abstrata, seja a mais complexa possível. Basta para isso que conheçamos os sinais necessários para expressar e o conteúdo a ser explicado. Com isso, compreendemos as dimensões da produtividade e criatividade que são itens importantes para serem entendidos no estudo da Língua.

Carvalho (2018) destaca que recursos didáticos são os materiais elaborados pelos próprios docentes a partir de objetos reutilizados ou novos, que tenham objetivo didático e auxiliem os professores nas suas atuações com os alunos surdos. A autora ainda apresenta que alguns autores utilizam outro termo como, por exemplo, Materiais Didáticos. Para Lorenzato (2010), por exemplo, Materiais Didáticos são todos e quaisquer instrumentos que possam ser úteis aos processos de ensino e de aprendizagem.

Entendemos, portanto, que, seja qual for o nome a serem utilizados, os recursos didáticos podem ser vistos como uma escolha metodológica auxiliar ao trabalho docente, envolvendo o planejamento das aulas, a organização das atividades didáticas sequenciais para que possam oportunizar as aprendizagens efetivas dos alunos diante dos conhecimentos matemáticos. Os jogos, por exemplo, são recursos didáticos que podem proporcionar sucesso no momento de sala de aula com os alunos. Porém, faz-se necessário que seja refletido sobre a importância, objetivos do jogo e que resultados trarão para as aprendizagens do aluno surdo.

Carvalho (2018) aponta que, no cenário inclusivo com surdos no ensino de matemática, faz-se de grande importância que o docente conheça os alunos, que "esteja atento às dificuldades de cada um, para que essas possam ser sanadas não se transformem em um problema irreversível” (p.51). A autora ainda acrescenta que

É necessário escutar, muito atentamente, seus alunos; observar seus comportamentos, atitudes, gestos, procedimentos, ideias, conhecimentos, utilizando sempre novas metodologias e práticas de ensino, buscando atualizar e adaptar suas propostas de trabalho a seus alunos. Para tais atitudes é necessária uma capacitação específica, para que esses profissionais da educação possam de fato possibilitar e contribuir com a aprendizagem 


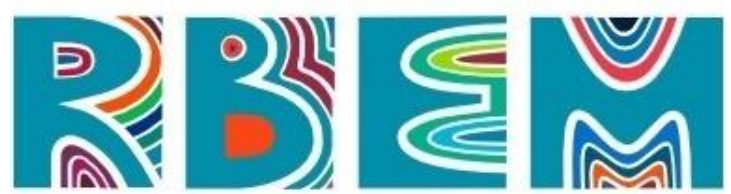

REVISTA BAIANA DE EDUCAÇÃO MATEMÁtICA

dos seus alunos. Para alcançar tais objetivos o professor deverá planejar aulas que sejam atrativas e prazerosas para seus alunos (CARVALHO, 2018, p. 51).

Assim, vemos a importância de pesquisarmos e cientificamente trabalharmos, no ensino de matemática dos alunos surdos, a perspectiva da construção de materiais pedagógicos que levem o surdo a possibilidades de aprendizagens em matemática de forma significativa.

\section{Metodologia da Pesquisa}

O projeto de pesquisa "Construção de materiais pedagógicos no ensino de matemática para alunos surdos" seguiu uma linha metodológica qualitativa que, segundo Minayo (2009), é uma pratica desenvolvida, sobretudo nas ciências sociais que se preocupa não com a quantificação, mas com os significados, aspirações, crenças, valores e atitudes, ou seja, com o que não deve ou não pode ser quantificado. Por esse viés o projeto buscou investigar uma metodologia significativa para o fazer pedagógico no ensino da matemática para os alunos surdos, averiguando assim as transformações as peculiaridades e especificardes existentes no ensino e na aprendizagem.

Inicialmente para a familiarização com a temática da pesquisa, precisou-se de reuniões semanais entre os pesquisadores na intenção de discutir sobre a execução do projeto. A partir daí, realizamos ainda as leituras bibliográficas que segundo Lakatos e Marconi (2011) diz ser a investigação de todos materiais como revistas, artigos, livros etc. Esses devem se relacionar a temática pesquisada na intenção do pesquisador conhecer e se aproximar do que já foi escrito sobre o que se pretende escrever. Nesse sentido foram pesquisadas algumas palavras chaves como material didático, matemática para alunos surdos, pedagogia visual, matemática e a metodologia significativa.

Por conseguinte, realizamos a pesquisa de campo. Minayo (2009) nos apresenta que a etapa de pesquisa de campo é importantíssima para que seja possível questionar a realidade com os conhecimentos adquiridos nas teorias pesquisadas em um processo que ela cita ser um contrapondo dialético. Com isso a prática de pesquisa foi realizada em um Centro Especializado na Área da Surdez. Nesse local seguiram-se alguns passos para que se chegassem às conclusões parcialmente retratadas nesse artigo, sendo o início a realização de 


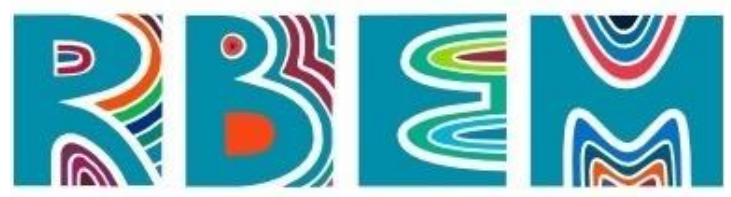

REVISTA BAIANA DE EDUCAÇÃO MATEMÁtICA

conversas formais com a professora de matemática a qual retratou as suas práticas metodológicas, as suas dificuldades e apresentou os materiais pedagógicos por ela utilizados. Um outro passo foi registrar por meio de fotografias o momento com os alunos surdos e principalmente os materiais encontrados, para que fossem analisados posteriormente na intenção de gerar registros e auxiliar na construção dos materiais pedagógicos.

A junção das pesquisas bibliográficas com a pesquisa de campo nos possibilitou construir os materiais pedagógicos buscando atender a necessidade do Centro Especializado na Área da Surdez (materiais voltados para a aprendizagem da matemática básica). Sendo esses materiais adaptados com a utilização da Libras, construídos com materiais recicláveis e inspirados em visualizações no YouTube e no Pinterest. No tópico a seguir, apresentamos alguns dos principais resultados teóricos e práticos que alcançamos ao longo do projeto.

\section{Resultados e Discussão}

O projeto "Construção de materiais pedagógicos no ensino de matemática para alunos surdos" gerou uma inquietação inicial de decodificação da temática para a compreensão de três aspectos, a cultura surda, a matemática e o surdo e por fim os materiais pedagógicos. Assim os estudos bibliográficos, conversas com a professora do Centro Especializado e observação de algumas práticas desta com os alunos surdos do local de pesquisa, auxiliaram nas percepções do assunto tema.

Como resultados obteve-se a clareza da importância de identificar a cultura surda apontada por Strobel (2008) descrita na introdução para que assim se distancie a ideia de denotar os surdos apenas por uma questão patológica e se aproxime da compressão da diferença cultural. Nesse aspecto, a linguagem matemática deve ser ensinada utilizando-se da pedagogia visual para o surdo, não por ser a matemática uma disciplina considerada difícil, mas por ser essa a pedagogia que valorize os processos de aprendizagem dos alunos alvo do projeto. Nesse sentido, Carvalho (2018) afirma que, o professor de matemática deve procurar estímulos visuais e que os recursos didáticos ganham sua importância, sendo eles qualquer material utilizado para a facilitação do ensino aprendizagem. Essa percepção da utilização dos materiais pedagógicos foi possível nas observações realizadas no campo de pesquisa o qual possui um número considerável de materiais como é demonstrado na imagem 1 . 

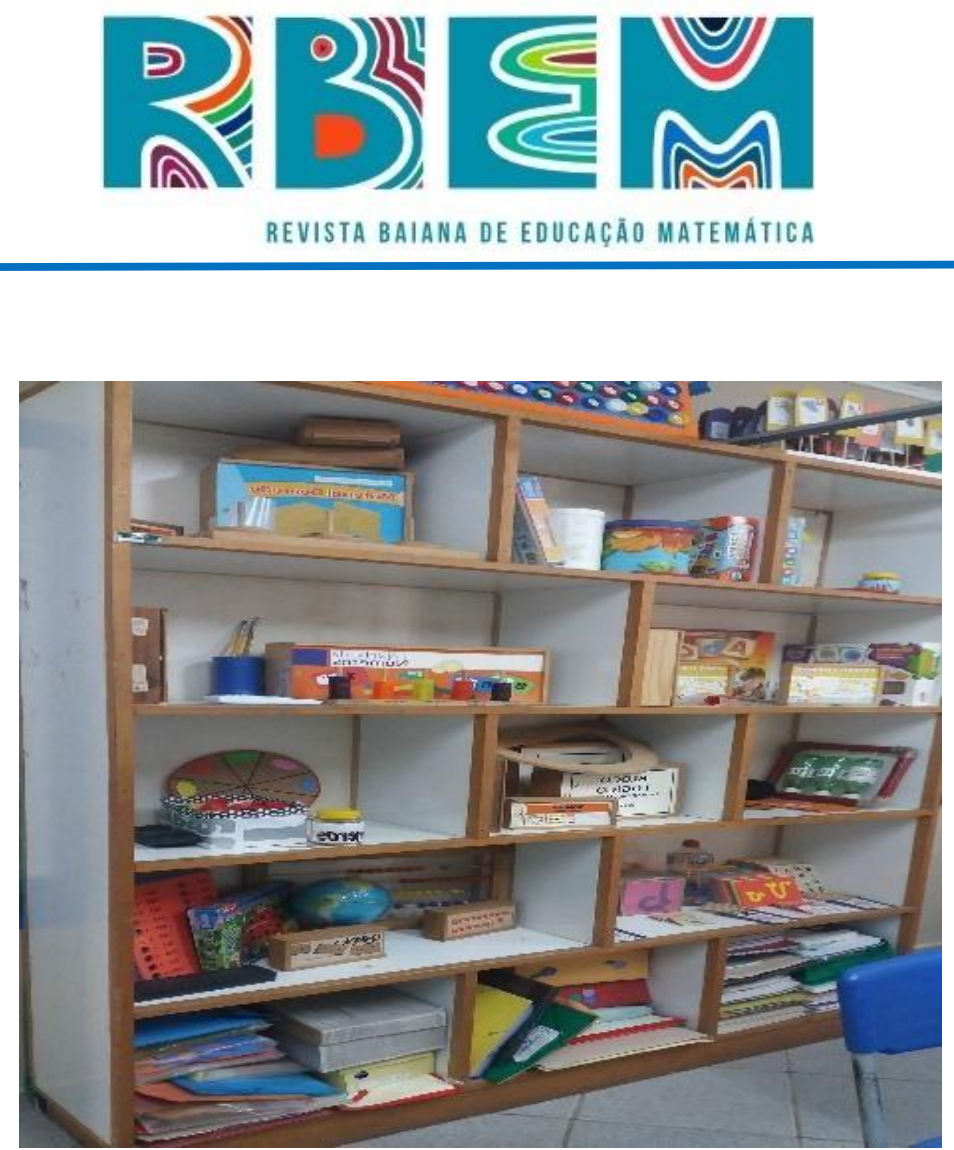

Imagem 1 - Materiais Encontrados No Lócus Da Pesquisa

Fonte: Os autores (2020)

Como podemos observar na imagem 1, o lócus da pesquisa apresentava alguns materiais didáticos, sendo estes materiais de aquisição comercial. Diante dessa situação,

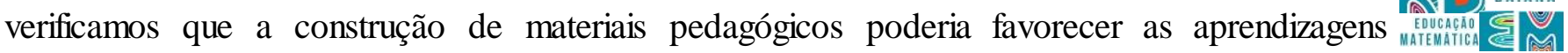
dos surdos, haja vista que no processo de criação e produção, poderíamos visualizar necessidades que estariam ocorrendo durante a execução do projeto no Centro.

A utilização desses recursos são geradoras de inquietações ao passo que não devem esses serem compreendidos apenas para um momento recreativo e nem devem serem aplicados de qualquer maneira, mas que sobretudo, objetiva está em consonância a um determinado conteúdo aplicado e que o professor tenha domínio sobre esse, sempre respeitando e conhecendo seus alunos (CARVALHO, 2018).

Nesse viés todos os materiais construídos, apontam para o atendimento das necessidades expostas e observadas no campo de pesquisa. Segue abaixo a imagem 2 e 3 que demonstram alguns dos materiais construídos, sendo eles adaptados e inspirados em outros materiais encontrados em sites como Pinterest e youtube. 


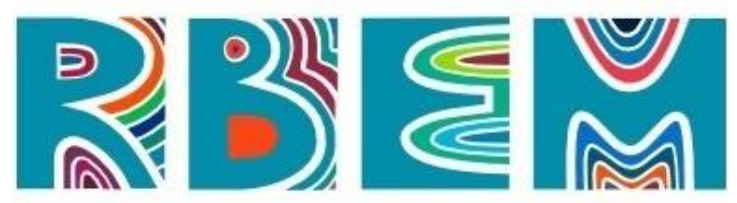

REVISTA BAIANA dE EDUCAÇÃo MATEMÁtICA

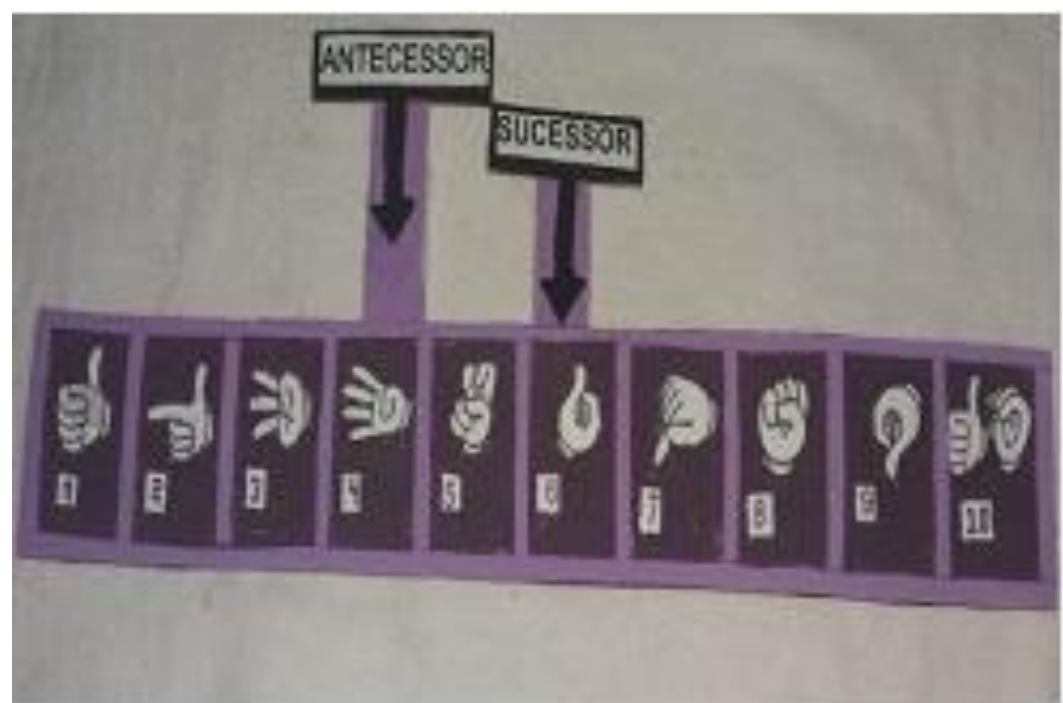

Imagem 2 - Um dos Materiais Construídos

Fonte: Os autores (2020)

A imagem 2 é um dos materiais construídos no ensino de matemática para surdos e objetivou auxiliar no ensino de dois conceitos matemáticos: o conceito de antecessor e o de sucessor. Na construção, utilizamos a sequencia de numeral indo-arábico do 1 ao 10 e acima inserimos as configurações de mãos dos números cardinais em Libras. O objetivo do material

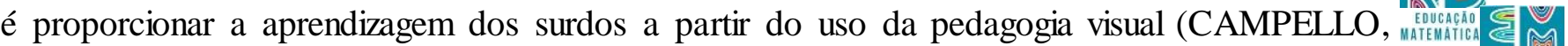
2007).

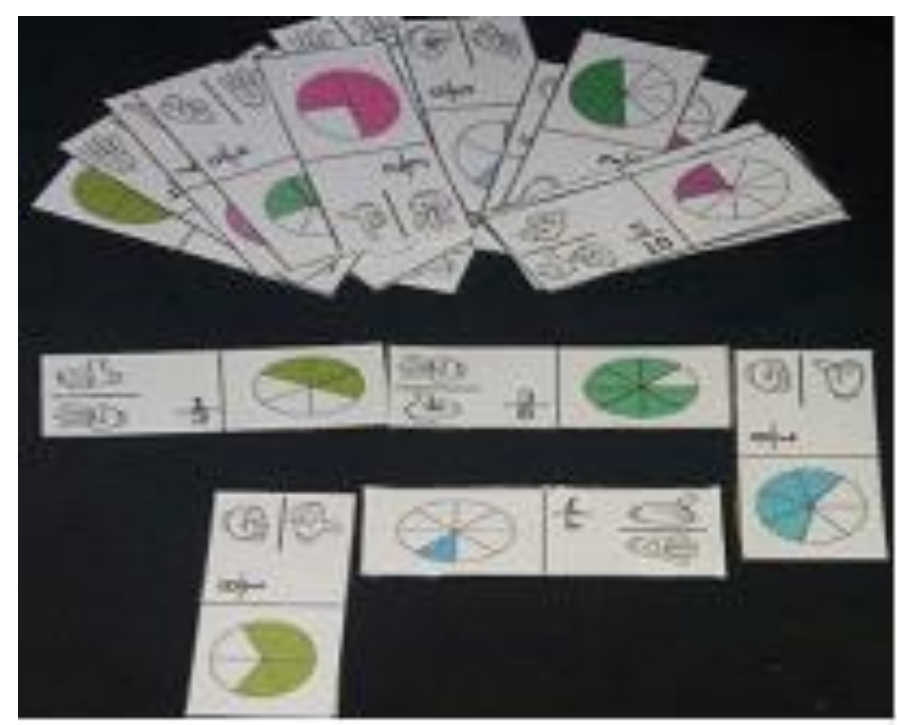

Imagem 3 - Um dos Materiais Construídos Fonte: Os autores (2020) 


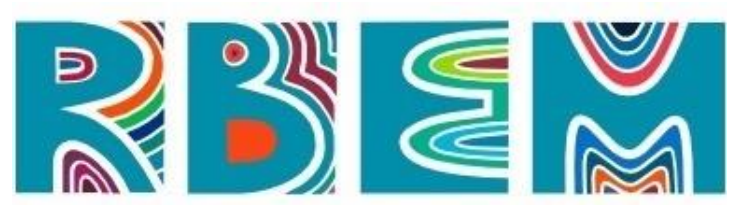

REVISTA BAIANA dE EDUCAÇÃo MATEMÁtICA

A imagem 3 é outro dos materiais construídos durante a execução do projeto no Centro Especializado e objetivou auxiliar no ensino de frações. O referido material é nominado de dominó de frações e foi adaptado de algumas observações, experiências e pesquisas da autoria. Na construção, utilizamos um dominó de frações e adaptamos as informações dos numerais indo-arábico e utilizamos o visual para chamar atenção e favorecer as aprendizagens dos surdos inserindo as configurações de mãos dos números cardinais em Libras. O objetivo do material também é estimular os surdos a partir dos aspectos visuais (CAMPELLO, 2007)

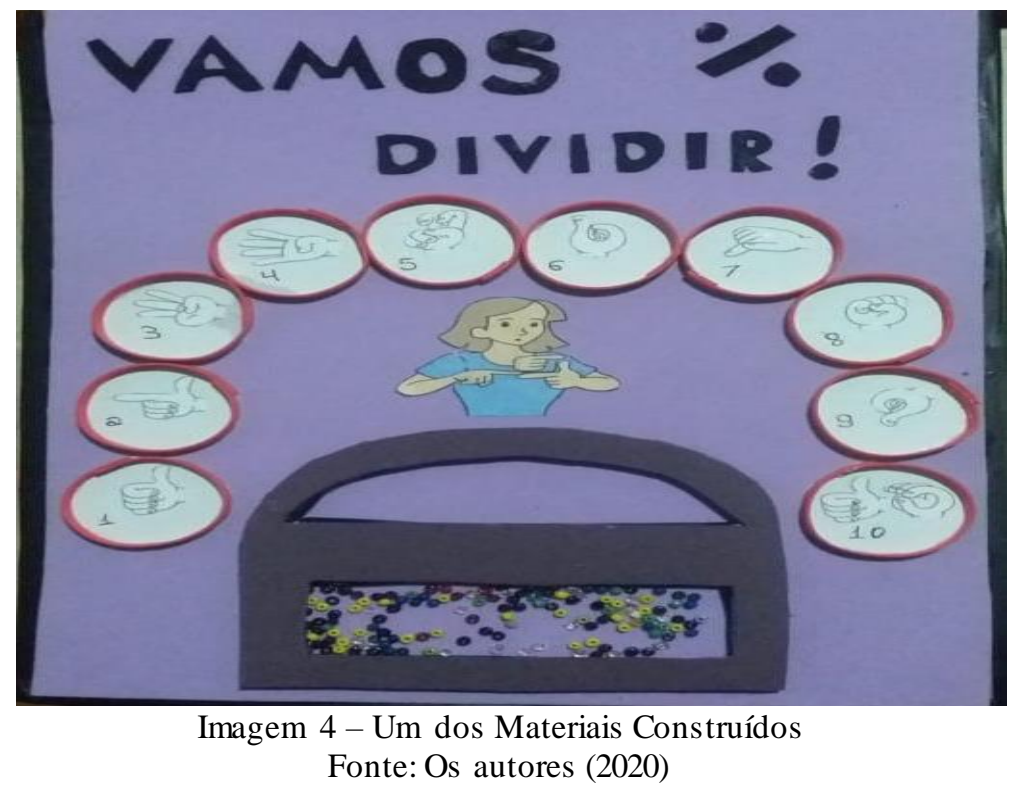

A imagem 4 é mais um dos materiais produzidos, nomeado de "vamos dividir", esse tem por intuito o ensino dos processos da divisão que é uma das quatro operações matemáticas. Utilizamos mais uma vez da ideia de explorar a pedagogia visual (CAMPELLO, 2007), através das configurações de mãos dos números em Libras e ainda da imagem retirada da apresentação de PowerPoint da professora surda Zanúbia Dada (2015) contendo a sinalização em Libras da palavra dividir. O visual é também explorado na utilização das miçangas, sendo elas ao serem manipuladas nesse material ternam-se facilitadoras na compreensão da operação matemática. Por exemplo, se o professor propor ao aluno que dívida o número quatro para dois, o aluno irá manipular quatro miçangas para a parte superior em seguida distribuirá igualmente essas quatro entre o compartimento do numero um e dois, ao finalizar o aluno visualizará e dialogará com o professor sobre o resultado. 


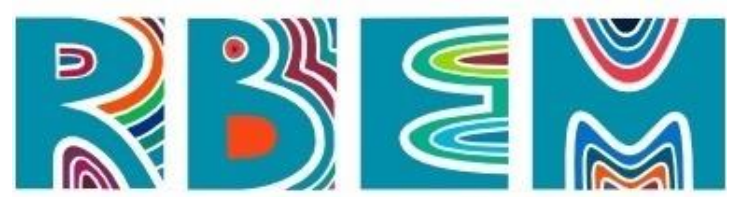

REVISTA BAIANA DE EDUCAÇÃO MATEMÁtICA

Ao longo de todas as etapas do projeto, principalmente durante as vivências no Centro Especializado, constatamos a importância da Libras para o desenvolvimento educacional do surdo. A Libras é a forma oficial de comunicação e expressão das comunidades surdas brasileiras (BRASIL, 2002; 2005). Assim, compreendemos esta ser indispensável para os processos de ensino e aprendizagem envolvendo o surdo. Destacamos ainda que durante a execução do projeto ficou bem evidenciado ainda a relevância do campo visual, "Não é possível aceitar, de forma alguma, o visual da língua de sinais e disciplinar a mente e o corpo das crianças surdas como sujeitos que vivem uma experiência auditiva" (SKLIAR, 2013, p. 28). Assim, os surdos eram constantemente estimulados por meio do seu campo linguístico que é o visual, seja observando ou manipulando os recursos utilizados nas aulas de matemática.

A experiência na construção dos materiais possibilitou perceber cada detalhe que devem ser levados em conta na construção dos materiais, como a compreensão dos conteúdos didáticos e se esses pode ser desenvolvido ou não por meio dessa metodologia, a aplicação da Libras nos materiais e ainda o tamanho do material etc. Os materiais construídos auxiliaram na aprendizagem das operações e noções básicas da matemática, sendo esses conteúdos mais fáceis de serem compreendidos por meio dos recursos didáticos.

\section{Considerações Finais}

Compreendemos que este projeto teve grande relevância e atualidade, pois sabemos que a sociedade brasileira passa por transformações e que a educação, enquanto fio condutor essencial em uma sociedade, também tem sofrido constantes alterações. Uma das transformações é a inclusão de pessoas surdas. Sabemos que diversas situações ocorrem para que os surdos tenham dificuldade no processo de inclusão nas escolas brasileiras. Além do advento das legislações contemporâneas já citadas ao longo do texto, vemos que os surdos têm os direitos assegurados enquanto membros da sociedade brasileira. É necessário que haja reflexões acerca do ensino e a aprendizagem desses alunos. Especificamente no ensino de matemática, que é uma disciplina considerada de difícil aprendizagem e com uma linguagem codificada. 


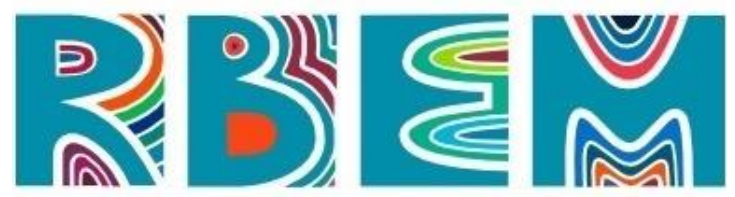

REVISTA BAIANA DE EDUCAÇÃO MATEMÁtICA

Vemos que o uso de materiais concretos construídos para serem usados nas aulas de matemática pode ser favorável e contribuirão para os surdos. Assim, o projeto buscou ainda levar os bolsistas a participar da investigação e da construção dos materiais pedagógicos, atividades em que irão crescer cientificamente e contribuir para uma educação inclusiva de surdos de fato que possa ser efetiva.

Dentro de todas as proposições destacadas nesse texto, o projeto "Construção de materiais pedagógicos no ensino de matemática para alunos surdos" proporcionou indagações e formulações científicas que motivaram e auxiliaram as práticas educativas na perspectiva de reformulações de metodologias que torne a matemática acessiva para a aprendizagem dos alunos surdos.

Dentro das experiências vivenciadas se evidencia que a construção de materiais pedagógicos e a utilização do mesmo deve sempre partir da necessidade do aluno percebida pelo professor, sendo esse material o mediador por auxiliar a percepção visual do surdo, mas não como o único meio de aprendizagem.

O projeto como fruto do ensino pesquisa e extensão que é o que constitui a Universidade possibilita que seus resultados possam contribuir para o campo teórico e prático de maneira que auxilie a formação e atuação dos professores no trabalho com a matemática e os alunos surdos, além de instigar futuras pesquisas na área, buscando reconhecer principalmente a participação dos surdos na escolha de uma melhor metodologia de ensino.

\section{Referências}

BORGES, Fábio Alexandre; NOGUEIRA, Clélia Maria Ignatius. Um panorama da inclusão de estudantes surdos nas aulas de matemática. In: NOGUEIRA, Clélia Maria Ignatius (Org.). Surdez, inclusão e matemática. 1. ed. Curitiba: CRV, p. 44-70, 2013.

BRASIL. Constituição da República Federativa do Brasil. Brasîlia, DF: Senado Federal: Centro. 1988.

BRASIL. Decreto $n^{o}$. 5626, de 22 de dezembro de 2005. Regulamenta a Lei 10.436, de 24 de abril de 2002 que dispõe sobre a Língua Brasileira de Sinais - Libras, e o Art.18 da Lei no 10.098 de 19 de dezembro de 2000. Brasilia, 2005.

BRASIL. Lei de Diretrizes e Bases da Educação Nacional (LDBEN). Lei Federal n. ${ }^{\circ}$ 9.394, de 26/12/1996. 


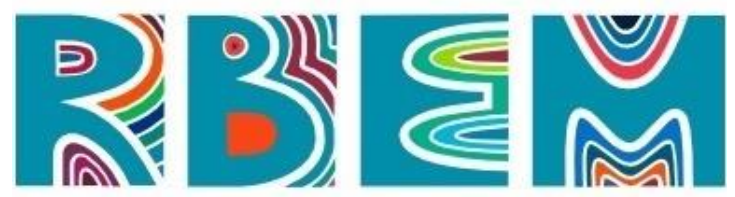

REVISTA BAIANA DE EDUCAÇÃO MATEMÁtICA

BRASIL. Lei $n^{\circ}$. 13.146, de 06 de julho de 2015. Institui a Lei Brasileira de Inclusão da Pessoa com Deficiência (Estatuto da Pessoa com Deficiência). Brasília, 2015.

BRASIL. Lei $n^{o} 10.436$ de 24 de abril de 2002. Dispõe sobre a Língua Brasileira de Sinais Libras, e dá outras providências. Brasilia, 2002.

CAMPELlO, Ana Regina e Souza. Pedagogia visual: sinal na educação dos surdos. In: QUADROS, R. M. de; PELIN, G. (orgs). Estudos Surdos II. Petrópolis: Arara Azul. p. 100$131,2007$.

CARVALHO, Carla Cristiana Coelho. Laboratório de recursos didáticos como intervenções para o ensino de matemática para alunos surdos. 2018, $73 \mathrm{f}$. Trabalho de Conclusão de Curso (Licenciatura Plena em Matemática). Universidade Federal do Sul e Sudeste do Pará. Santana do Araguaia - Pará, 2018.

COSTA, Walber Christiano Lima da. O ensino de matemática na educação inclusiva: uma análise da formação de professores. Trabalho de Conclusão de Curso (Licenciatura Plena em Pedagogia). Universidade do Estado do Pará. Belém - Pará, 2017.

COSTA, Walber Christiano Lima da; MENEZES, Gabrielle Janaina Barros de; CARVALHO, Carla Cristiana Coelho; LIMA, Valdineia Rodrigues. Recursos didáticos no ensino de matemática: uma proposta na educação de surdos. In: Revista GPES - Estudos Surdos. Marabá - PA, v. 1. n. 1 (2018) - ISSN 2595 - 9832.

DADA, Zanúbia. Matematica em Libras: Parte 4 quatro operações [PowerPoint slides]. Ilustração de Mauro Lúcio Gondin. Retrieved from https://pep.ifsp.edu.br/images/PDF/CSP/documentos-sociopedagogicos/Matemtica--Operaes.pdf. 2015.

FREIRE, Paulo. Pedagogia do oprimido. $65^{\circ}$ ed. Rio de Janeiro: Paz e Terra, 1987. 256p.

GESSER, Audrei. LIBRAS?: Que língua é essa? : crenças e preconceitos em torno da língua de sinais e da realidade surda. São Paulo. Parábola Editorial, 2009.

LAKATOS, Eva Maria; MARCONI, Marina de Andrade. Fundamentos de metodologia cientifica. São Paulo: Atlas, 2011.

LORENZATO, Sérgio (Org.). O Laboratório de Ensino de Matemática na Formação de Professores. 3. ed. Campinas-SP: Autores Associados, 2010. (Coleção Formação de Professores).

MANTOAN, Maria Teresa Egler. Inclusão Escolar: o que é? por quê? como fazer? São Paulo: Moderna, 2003.

MINAYO, Maria Cecilia de Souza. Trabalho de campo: contexto de observação, interação e 


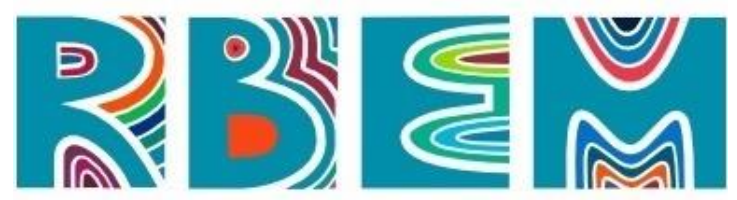

descoberta In. MINAYO, Maria Cecilia de Souza; DESLANDES, Sueli Ferreira; GOMES, Romeu (Org). Pesquisa social: teoria, método e criatividade. 28 ${ }^{\mathrm{a}}$. ed. Petrópolis: Vozes, 2009.

SKLIAR, Carlos. A localização política da educação bilíngue para surdos. Em C. Skliar (Org.), Atualidade da Educação Bilíngue para Surdos: Interfaces entre Pedagogia e Linguística (Vol.1, 4ª ed., pp. 7-14). Porto Alegre, RS: Mediação, 2013.

STROBEL, Karin. As imagens do outro sobre a cultura surda. Florianópolis: UFSC, 2008 .

Artigo submetido em: 14/11/2020

Artigo aceito em: 17/12/2020 